\title{
Unraveling The Anion/Ligand Interplay in The Reaction Mechanism Of Gold(I)-Catalyzed Alkoxylation Of Alkynes
}

\author{
Lorenzo D'Amore, ${ }^{a}$ Gianluca Ciancaleoni, ${ }^{b}$ Leonardo Belpassi, ${ }^{c}$ Francesco Tarantelli,,${ }^{c, d}$ \\ Daniele Zuccaccia, ${ }^{e}$ and Paola Belanzoni ${ }^{c, d *}$
}

\author{
a Institut de Química Computacional i Catàlisi (IQCC), Departament de Química, Universitat de Girona, \\ Campus Montilivi, 17003 Girona, Catalonia, Spain \\ ${ }^{b}$ Dipartimento di Chimica e Chimica Industriale, Università di Pisa, via Giuseppe Moruzzi 13, I-56124, Pisa, \\ Italy \\ c Istituto di Scienze e Tecnologie Molecolari del CNR (CNR-ISTM) c/o Dipartimento di Chimica, Biologia e \\ Biotecnologie, Università di Perugia, via Elce di Sotto 8, I-06123 Perugia, Italy \\ ${ }^{d}$ Dipartimento di Chimica, Biologia e Biotecnologie, Università di Perugia, via Elce di Sotto 8, I-06123 \\ Perugia, Italy \\ e Dipartimento di Scienze Agroalimentari, Ambientali e Animali, Sezione di Chimica, Università di Udine, via \\ Cotonificio 108, I-33100 Udine, Italy
}

\begin{abstract}
In this work DFT calculations have been performed to investigate the anion/ligand interplay in the reaction mechanism of alkoxylation of alkynes promoted by gold(I) catalysts of general formula $[\mathrm{L}-\mathrm{Au}-\mathrm{X}] \mathrm{L}$ $=\mathrm{NHC}, \mathrm{P}\left({ }^{\mathrm{t}} \mathrm{Bu}\right)_{3}$ and $\left.\mathrm{X}=\mathrm{OTs}^{-}, \mathrm{OTf}^{-}, \mathrm{BF}^{-}, \mathrm{TFA}^{-}\right)$on the basis of experimental available data. The observed catalytic efficiency trend in this series of compounds strictly depends on the specific anion/ligand combination used, thus suggesting that it cannot be estimated by evaluating the properties of $L$ and $X$ separately. Similarly to the $[\mathrm{NHC}-\mathrm{Au}-\mathrm{X}]$, for the $\left[\mathrm{P}\left({ }^{\mathrm{t}} \mathrm{Bu}\right)_{3}-\mathrm{Au}-\mathrm{X}\right]$ catalyst series, we demonstrate that the anion effect in the reaction mechanism can be predicted on the basis of its coordinating/proton acceptor properties. A comparison between the $\mathrm{P}\left({ }^{(} \mathrm{Bu}\right)_{3} / \mathrm{OTs}^{-}$and $\mathrm{NHC} / \mathrm{OTs}$ settings shows that the anion/ligand interplay has a crucial role on the nucleophilic attack step of the reaction mechanism. The ChargeDisplacement $(C D)$ analysis reveals that the activation of the unsaturated hydrocarbon multiple bond (alkyne) by the $[\mathrm{L}-\mathrm{Au}]^{+}$fragment depends both on the ligand withdrawing ability at the outer region of the $\mathrm{CC}$ bond and on the counterion affinity to the cationic fragment, both affecting in the opposite way the electrophilic character of the alkyne at the transition state.
\end{abstract}

\section{Introduction}

Despite the relatively young age of homogeneous gold catalysis, in the last decade the use of gold complexes in homogeneous conditions has increased enormously. ${ }^{1-15}$ Most of the gold-catalyzed processes can be classified as nucleophilic additions to carbon-carbon unsaturated bond, promoted by gold catalysts of general formula [L-Au-X] (where $L$ is an ancillary lingand and $X$ is a counterion). Almost all the proposed mechanisms follow the catalytic cycle shown in Scheme 1, sometimes in the presence of additional sub-cycles. ${ }^{16}$ The initial gold complex [L-Au-X] (initial complex IC, inner-sphere ion pair, ISIP) coordinates to the unsaturated hydrocarbon acting as a Lewis acid in the pre-equilibrium step (reactant 
complex RC, outer-sphere ion pair, OSIP). The hydrocarbon multiple bond is consequently activated towards the nucleophilic attack by the nucleophile $[\mathrm{Nu}-\mathrm{H}]$, forming an organogold intermediate (intermediate I). Finally, the gold-carbon bond of the intermediate is typically cleaved by a proton (protodeauration step) to yield the product complex PC and regenerate the catalyst.

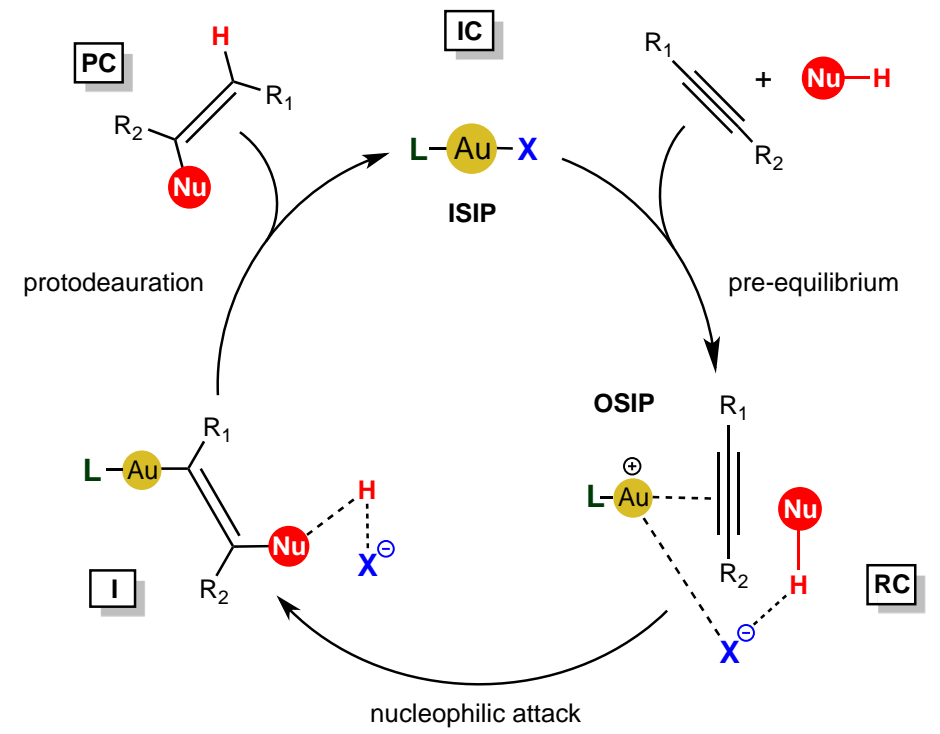

Scheme 1. Proposed Gold(I) Catalytic Cycle for Alkyne Alkoxylation Reaction.

Within the above catalytic cycle, the impact of the ligand has been deeply investigated through both kinetic and mechanistic studies ${ }^{17-20}$ and it is now generally accepted that the ligand plays a major role in modulating the acidic character of the gold fragment and affects the stability of the postulated intermediates. ${ }^{21-26}$ In particular, electron withdrawing ligands promote electrophilic activation of the substrate favoring the reaction when the rate determining step (RDS) is the nucleophilic attack, whereas electron donating ligands accelerate the reaction when the protodeauration is the RDS. ${ }^{20,27,28}$ On the other hand, also the anion plays a crucial role, influencing the catalytic activity, ${ }^{29-33}$ the regioselectivity ${ }^{34-38}$ and even the stereoselectivity ${ }^{39,40}$ of the process. Moreover, it has been well established that the structure of the catalyst ${ }^{41}$ and of the intermediates ${ }^{42-47}$ are affected by the counterion. ${ }^{26,48}$ Nevertheless, although several experimental data reporting a significant "anion effect" in gold catalysis have been published, ${ }^{49}$ the sizeable accumulation of empirical knowledge is only partially accompanied by a deeper rationalization. Within this scenario, we recently combined extensive experimental and computational studies ${ }^{50-52}$ to understand the role of the anion in all the steps of the reaction mechanism of the gold-catalyzed alkoxylation of alkynes (i.e. pre-equilibrium, nucleophilic attack and protodeauration, Scheme 1) using a carbene-based NHC ligand. The main results have shown that the nucleophilic attack (the RDS) is anionassisted through the formation of a hydrogen bond $(\mathrm{HB})$ with the nucleophile and that in this step the anion acts both (i) as a template, holding the nucleophile at the right position for the outer-sphere attack and (ii) as a hydrogen-bond acceptor, enhancing the nucleophilicity of the attacking alcohol. However, in the preequilibrium step, the anion (iii) can also be responsible for two competing deactivation pathways of the catalyst, by either its strongly coordinating and/or basicity power, preventing the alkyne coordination through the formation of unreactive tricoordinated species or forming free alkoxide species, which poisons the catalyst. Finally, in the protodeauration step, the anion iv) participates in the proton shuttle, favoring the 
hydrogen transfer..$^{53}$ Furthermore, by considering a wide series of counterions, we rationalized the anion effect in the reaction pathway simply on the basis of its coordinating ability/proton acceptor capacity and of the geometry of its anchoring group. ${ }^{52}$ The success of this modeling scheme prompted us to extend our previous studies, ${ }^{50-52}$ on the basis of recent experimental results obtained by Zuccaccia et al. ${ }^{54}$ for the methoxylation of 3-hexyne with $\mathrm{L}=\mathrm{P}\left({ }^{(} \mathrm{Bu}\right)_{3}, \mathrm{PPh}_{3}, \mathrm{PArF}$ (tris(3,5-bis(trifluoromethyl)phenyl)-phosphine), NHC (1,3-bis(2,6-diisopropylphenyl)-imidazol-2-ylidene) and the anion series $\mathrm{X}=\mathrm{BF}_{4^{-}}$, OTf(trifluoromethanesulfonate), OTs ${ }^{-}$( $p$-toluensulfonate), $\mathrm{TFA}^{-}$(trifluoroacetate). According to these experimental studies, all the gold complexes bearing phosphane ligands follow a similar trend, reaching efficient catalytic performances with noncoordinating and weakly basic anions (OTf- $>\mathrm{BF}_{4}^{-}>\mathrm{OTs}^{-}>\mathrm{TFA}^{-}$), at a variance with the NHC-based complexes, for which the highest activity is achieved for intermediate coordinating ability and basicity of the counterion (OTs ${ }^{-} \mathrm{OTf}^{-}>\mathrm{BF}_{4^{-}}>\mathrm{TFA}^{-}$) (see Figure S1 and Table S1 in the Supporting Information for an anion coordination power estimate). In particular, the best settings for this reaction are represented by $\mathrm{P}\left({ }^{\mathrm{t}} \mathrm{Bu}\right)_{3} / \mathrm{OTf}-$ and $\mathrm{NHC} / \mathrm{OTs}^{-}$. Thus, the observed catalytic efficiency strictly depends not only on the counterion for a given ligand but also on the ligand for a given counterion, namely on the specific combination of anion/ligand used, suggesting that these two species do not act independently but in a synergic way. As a consequence, the catalytic activity of a given [L-Au-X] catalyst should not be estimated by evaluating the properties of $L$ and $X$ separately, but rather on the basis of their best combination. This intriguing scenario pushed us to investigate this important ligand/anion correlation factor in gold catalysis, whose rational understanding is still lacking to our knowledge, except for the role of the ligand in determining the ion pair structure of the complexes ${ }^{26}$ and how the latter influences the catalytic performances of the gold catalyst. ${ }^{32}$

In this paper we focus on the different catalytic behavior observed for $\mathrm{P}\left({ }^{\mathrm{t}} \mathrm{Bu}\right)_{3} / \mathrm{OTs} \mathrm{s}^{-}$with respect to that of

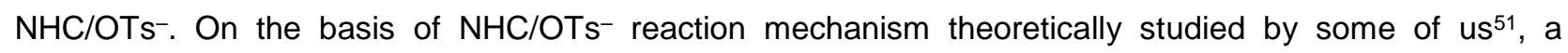
possible explanation could rely on the OTs- different ability to act as a template (holding the nucleophile for the outer sphere attack and as a hydrogen bond acceptor) when NHC is replaced with $\mathrm{P}\left({ }^{(} \mathrm{Bu}\right)_{3}$. Alternatively, the coordination power affinity of the OTs- with the gold could be different when $\mathrm{P}\left({ }^{\mathrm{t}} \mathrm{Bu}\right)_{3}$ rather than NHC are bound to gold used as ancillary ligands, for electronic or steric reasons, which could affect affecting the structure of the catalyst, intermediates or even transition states. To understand these differences, at first we investigate through DFT calculations the anion effect in the reaction mechanism using the ligand $\mathrm{L}=\mathrm{P}\left({ }^{(} \mathrm{Bu}\right)_{3}$ and varying the anion $\mathrm{X}^{-}$within the $\mathrm{BF}_{4^{-}}, \mathrm{OTf}^{-}, \mathrm{OTs}^{-}$, and $\mathrm{TFA}^{-}$series, namely the $\left[\mathrm{P}\left({ }^{\mathrm{t}} \mathrm{Bu}\right)_{3}-\mathrm{Au}-\mathrm{X}\right]\left(\mathrm{X}^{-}=\mathrm{BF}_{4}^{-}, \mathrm{OTf}^{-}, \mathrm{OTs}^{-}, \mathrm{TFA}^{-}\right)$catalysts, proving the consistency of our proposed mechanism in ref. ${ }^{51}$ and closely comparing the $\mathrm{P}\left({ }^{\mathrm{t}} \mathrm{Bu}\right)_{3} / \mathrm{OTs}^{-}$vs. the $\mathrm{NHC} / \mathrm{OTs}^{-}$catalyzed reaction mechanism steps. Successively, through the Charge-Displacement (CD) analysis ${ }^{55,56}$, we study the activation of the unsaturated hydrocarbon multiple bond (alkyne) by the $[L-A u]^{+}$fragment $\left(L=P\left({ }^{+} B u\right)_{3}\right.$, $\mathrm{NHC}$ ) both in the presence and without the OTs anion, providing a quantitative picture of the actual electron charge redistribution at the substrate and, finally, an understanding of how the anion/ligand interplay affects the reaction. 


\section{Methodology}

\section{Reaction Model}

Complex $\left[\mathrm{P}\left({ }^{\mathrm{t}} \mathrm{Bu}\right)_{3}-\mathrm{Au}-\mathrm{X}\right]$ has been chosen as catalyst, 2-butyne and methanol have been selected as substrate and nucleophile, respectively. The overall anion series $\mathrm{X}=\mathrm{BF}_{4}^{-}, \mathrm{OTf}^{-}, \mathrm{OTs}^{-}$and TFA ${ }^{-}$has been explored in our DFT calculations. Coherently with our previous work, ${ }^{51}$ two methanol molecules have been considered in the calculations since the inclusion of a second methanol is mandatory for the protodeauration step mediating the proton transfer in the case of $\mathrm{BF}_{4}^{-}$. For comparison with [NHC-Au-OTs] catalyst, the two isopropylphenyl groups of the ligand have been substituted with methyl groups (model $\mathrm{NHC}=1,3$-dimethylimidazol-2-ylidene) in order to reduce the computational effort. Despite the model [NHC-Au-OTs] catalytic mechanism with two methanol molecules has been already investigated in ref. ${ }^{51}$ (see Computational Details and Figure S9 in the SI of ref. ${ }^{51}$ for results), we repeated the calculations using the same computational details as those employed here for $\left[\mathrm{P}\left({ }^{\mathrm{t} B u}\right)_{3}-\mathrm{Au}-\mathrm{X}\right]$ (see below) for a consistent comparative study. All the species considered in this work are depicted in Scheme 2.
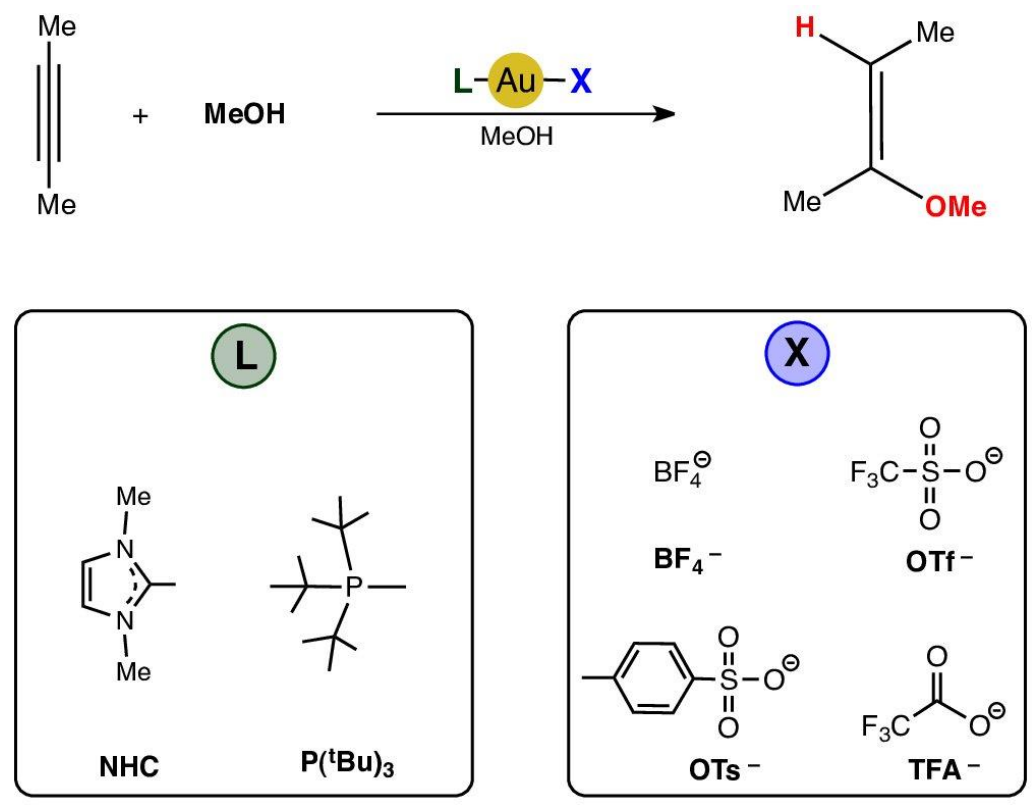

Scheme 2. Schematic representation of all the species considered in our DFT studied reaction.

\section{Computational Details}

A comprehensive computational DFT ${ }^{57-59}$ study was performed with Gaussian0960 program package to identify all the structures. For geometry optimizations, calculations were carried out using the GGA functional BP86 (DFT/BP86).61,62 Relativistic effects were treated with ECP core potential63 and all atoms were described with a def2-TZVP triple- $\zeta$ quality basis set. ${ }^{64}$ Frequency calculations at the same BP86 level of theory have been performed to identify transition states (one imaginary frequency). Final energies have been calculated using $\mathrm{ORCA}^{65}$ program package by single point perturbatively corrected doubly hybrid functional B2PLYP66 calculations on the optimized BP86 gas phase structures in conjunction with a def2- 
TZVP triple- $\zeta$ basis set for all atoms and ECP pseudopotential for gold to account for relativistic effects. This combined BP86 geometry optimization and B2PLYP energy calculation approach has been shown to give a high accuracy to describe gold species along reaction paths in previous benchmark studies (we refer to it as B2PLYP//BP86). ${ }^{67-69}$ The computational mechanistic analysis is presented in enthalpy energies due to the very small entropy contribution, as reported in the SI of our previous work. ${ }^{50}$ The ChargeDisplacement analysis on the optimized BP86 gas phase structures was performed at the DFT level of theory with the ADF2013.0170-72 program package, using the same BP86 functional. Relativistic effects were treated with the scalar zeroth-order regular approximation, ZORA model.73,74 All atoms were described with a Slater-type TZ2P triple- $\zeta$ quality basis set, using the frozen core approximation (1s for $B$, C, N, O, F; $2 p$ for $P, S ; 4 d$ for $A u$ ). All calculations were performed for closed shell singlet states.

\section{Charge-Displacement (CD) analysis}

The electron density changes occurring upon the chemical bond formation between two fragments $A$ and $B$ can be analyzed through the Charge-Displacement (CD) function ${ }^{55}$

$$
\Delta q(z)=\int_{-\infty}^{z} d z^{\prime} \int_{-\infty}^{\infty} \int_{-\infty}^{\infty} \Delta \rho\left(x, y, z^{\prime}\right) d x d y
$$

In this equation $\Delta \rho(x, y, z)$ is the electron density difference between the electron density of the complex $A B$ and that of the two non-interacting fragments $A$ and $B$ in the geometries they have in the overall complex. $A$ partial progressive integration of $\Delta \rho(x, y, z)$ along a suitable chosen bond axis $z$ yields the ChargeDisplacement function $\Delta q(\mathrm{z})(1)$. This function measures at each point $\mathrm{z}$ along a chosen axis $\mathrm{z}$ ' (typically the axis joining $A$ and $B$ fragments) the amount of electrons that, upon bond formation, moves across a plane perpendicular to this axis passing through z. Positive (negative) values of $\Delta q(\mathrm{z})$ correspond to electrons flowing in the direction of decreasing (increasing) $z^{\prime}$. A positive (negative) slope indicates regions of charge accumulation (depletion). To obtain well-defined measures of the net charge transfer (CT), CD function values at a plausible inter-fragment boundary can be taken. This choice is of course arbitrary, but a reasonable commonly used model is to take the CD function values at the so-called isodensity boundary, i.e. at the $z$ ' point where equal-valued isodensity surfaces of the fragments become tangent. ${ }^{56}$ The complexes studied in this work through $C D$ analysis have general formula [L-Au-S $]^{+}$(where $S=2$-butyne) or $[(\mathrm{L}-\mathrm{Au}-\mathrm{S}) \mathrm{X}]$ (where $\left.\mathrm{X}=\mathrm{OTs}^{-}\right)$. Since the LAu-S or LAu-SX bond is under investigation, the appropriate fragments are the $[\mathrm{L}-\mathrm{Au}]^{+}$moiety and $\mathrm{S}$ or $\mathrm{SX}$, and the $\mathrm{z}$ reference axis joins the $\mathrm{Au}$ and $\mathrm{CC}$ bond midpoint (when $S$ coordinates $\eta^{2}$ to gold in [L-Au-S] $]^{+}$) or Au and a $C$ atom (when $S$ coordinates $\eta^{1}$ to gold in [(L-AuS)X].) The CD function provides a thorough, spatially detailed picture of the total charge flow between the ligand-metal and the substrate fragments. The CD function can also provide valuable additional information concerning the substrate $\mathrm{CC}$ bond polarization. A quantitative estimate of such a polarization is given by the amount of charge flowing across a plane perpendicular to the $\mathrm{CC}$ bond either through its midpoint (for $[\mathrm{L}-\mathrm{Au}-\mathrm{S}]^{+}$complexes) or through a carbon atom (for $[(\mathrm{L}-\mathrm{Au}-\mathrm{S}) \mathrm{X}]$ complexes) (i.e. the $\mathrm{CD}$ function value at $z^{\prime}=r$ cC/2 or at $z^{\prime}=r_{c}$, respectively). All of the CTs reported in this work refer either to the CTs taken at the isodensity boundary (denoted as $\mathrm{CT}_{\text {iso }}$ ) or at the alkyne CC (denoted as $C T_{C C}$ ). The $C D$ analysis has proven to be a stable method with respect to computational settings such as basis set quality and exchange-correlation functional. ${ }^{75}$ 


\section{Results and discussion}

\section{Reaction Mechanism}

As mentioned in the Introduction, we first investigate the anion effect in the $\left[\mathrm{P}\left({ }^{\mathrm{t}} \mathrm{Bu}\right)_{3}-\mathrm{Au}-\mathrm{X}\right]\left(\mathrm{X}^{-}=\mathrm{BF}_{4^{-}}, \mathrm{OTf}^{-}\right.$, $\mathrm{OTs}^{-}, \mathrm{TFA}^{-}$) catalyzed reaction mechanism. We initially focus on the phosphine-based gold catalyst in the presence of the OTs ${ }^{-}$anion, $\left[\mathrm{P}\left({ }^{(} \mathrm{Bu}\right)_{3}-\mathrm{Au}-\mathrm{OTs}\right]$. The calculated initial complex IC, reactant complex RC, intermediate I, product complex PC, transition state TSI for the methanol nucleophilic attack to 2-butyne and transition state TSII for the protodeauration step are shown in Figure 1. The most stable species formed by the catalyst, the alkyne and the nucleophile has been calculated to be the anion-coordinated IC, which has been taken as the zero point energy. In the initial complex IC the OTs ${ }^{-}$anion coordinates to the metal center $\left(\mathrm{Au}-\mathrm{O}\left(\mathrm{OTs}^{-}\right)=2.091 \AA\right.$ ) while forming a $\mathrm{HB}$ with one of the two methanol molecules $\left(\mathrm{MeOH} \cdots \mathrm{O}\left(\mathrm{OTs}^{-}\right)=1.776 \AA\right)$. After tosilate tosylate substitution by 2-butyne (pre-equilibrium step), in the reactant complex $\mathbf{R C}$ the two methanol molecules form a "chain" connecting the 2-butyne and the anion, the latter acting as a template and holding the nucleophile at the right position for an outer sphere attack. In $\mathbf{R C}$ the OTs ${ }^{-}$anion interacts through its oxygen atoms with the metal center $\left(A u \cdots O\left(\mathrm{OTs}^{-}\right)=3.221 \AA\right.$ ) while forming a $\mathrm{HB}$ with the auxiliary "bridging" methanol $\left(\mathrm{MeOH} \cdots \mathrm{O}\left(\mathrm{OTs}^{-}\right)=1.695 \AA\right)$. The formation of $\mathbf{R} \mathbf{C}$ from the corresponding IC is thermodynamically unfavored by $2.6 \mathrm{kcal} / \mathrm{mol}$. For the nucleophilic attack step of $\mathrm{MeOH}$ to the butyne-coordinated species, a transition state is calculated with an activation energy barrier of $13.0 \mathrm{kcal} / \mathrm{mol}$. In the TSI the methanol attack at alkyne $\mathrm{C} 1$ causes a rearrangement in the coordination of the Au atom, forming an almost direct bond with the $\mathrm{C} 2$ carbon atom that lies at $2.131 \AA$ from it, while that between $\mathrm{C} 1$ and gold is elongated $(2.737 \AA)$. On the whole, the characteristic template structure of $\mathbf{R C}$ with the anion between $\mathrm{Au}$ and the nucleophile is retained in TSI. In the latter, the distance between $\mathrm{C} 1$ and the oxygen atom of the attacking methanol is $2.093 \AA$ and the distance between oxygen of OTs- ${ }^{-}$and the metal center is $3.192 \AA$. An incipient abstraction of the proton from the "bridging" methanol by OTs ${ }^{-}$can be observed $\left(\mathrm{MeO}-\mathrm{H}=1.020 \AA\right.$ and $\mathrm{MeOH} \cdots \mathrm{O}\left(\mathrm{OTs}^{-}\right)=1.589 \AA$ ). This causes the weakening of the $\mathrm{O}-\mathrm{H}$ bond of the attacking methanol $(\mathrm{MeO}-\mathrm{H}=1.042 \AA)$, thus triggering a proton shuttle chain. TSI evolves towards the formation of the intermediate $\mathbf{I}$, where the "bridging" methanol acts both as a proton acceptor from the nucleophile and as a proton donor to the anion. Subsequently in TSII, the "bridging" methanol mediates the proton transfer from the anion (by acting as a proton acceptor from OTs ${ }^{-}$) towards the C2 (by acting as a proton donor to C2) for the protodeauration. The energy barrier for this step is calculated to be $6.5 \mathrm{kcal} / \mathrm{mol}$. In the final product complex PC the hydrogen is in trans position with respect to methoxy and the gold center coordinates to the product via its unsaturated double bond and it weakly interacts with the anion. The product complex PC is stabilized with respect to intermediate I by $16.6 \mathrm{kcal} / \mathrm{mol}$, while the overall reaction from IC to $\mathbf{P C}$ is exothermic by $17.4 \mathrm{kcal} / \mathrm{mol}$ with an activation energy barrier of 15.6 $\mathrm{kcal} / \mathrm{mol}$. For the same reaction, fixing the ligand $\mathrm{L}=\mathrm{P}\left({ }^{\mathrm{t}} \mathrm{Bu}\right)_{3}$ and varying the anion $\mathrm{X}=\mathrm{OTf}^{-}, \mathrm{BF}_{4}^{-}, \mathrm{TFA}^{-}$, similar geometries of the initial complex, reactant complex, intermediate, transition states and product complex have been calculated and comparable potential energy profiles have been found. In Figure 2 the reaction paths with all of the different anions are depicted for comparison (see Figures S2, S3 and S4 in the Supporting Information for the complete paths with the structures and relative energies of all the species 
studied). Coherently with our previous works ${ }^{50-52}$, the most stable species formed by the catalyst, alkyne and the nucleophile have been calculated to be the anion-coordinated initial complex $\mathbf{I} \mathbf{C}_{\mathbf{x}}$ for medium to high coordinating ability anions $\left(\mathrm{X}=\mathrm{OTs}^{-}, \mathrm{TFA}^{-}\right)$or the butyne-coordinated reactant complex $\mathbf{R} \mathbf{C}_{\mathbf{x}}$ for medium to low coordinating ability anions $\left(\mathrm{X}=\mathrm{OTf}^{-}, \mathrm{BF}_{4}^{-}\right)$which have been taken as the zero point energy, respectively.

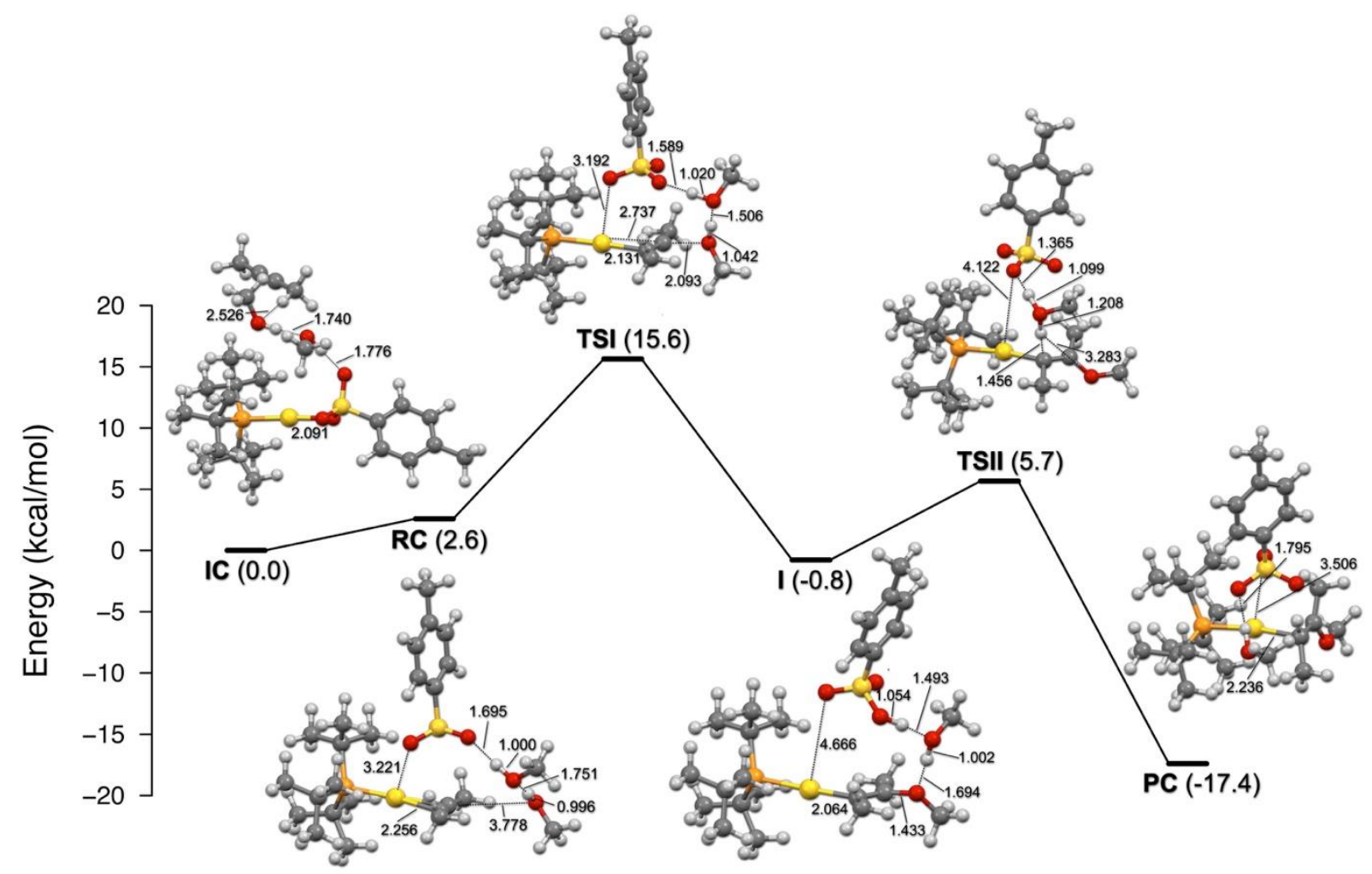

Figure 1. Reaction path for the methanol addition to 2-butyne catalyzed by [L-Au-X], with $L=P\left({ }^{t} B u\right)_{3}$ and $X=O T s^{-}$. Initial complex IC, reactants complex RC, intermediate I, product complex PC, transition state TSI for the nucleophilic attack step and TSII for the protodeauration step are shown. Energies values $(\mathrm{kcal} / \mathrm{mol})$ refer to IC, taken as zero point energy. Bond lengths are in angstroms.

In Table 1 the overall calculated activation energy barriers within the anion series together with the corresponding experimental TOF values ${ }^{54}$ are reported. The activation parameters for the nucleophile attack (the RDS) show good agreement with the experimental TOF values of the reaction, in which the order of the catalytic efficiency of the $\left[\mathrm{P}\left({ }^{\mathrm{t}} \mathrm{Bu}\right)_{3}-\mathrm{Au}-\mathrm{X}\right]$ complexes follow the same trend we found theoretically (e.g. $\mathrm{X}=\mathrm{OTf}^{-}>\mathrm{BF}_{4}^{-}>\mathrm{OTs}^{-}>\mathrm{TFA}^{-}$). In the presence of medium to low coordinating ability anions such as $\mathrm{OTf}^{-}$and $\mathrm{BF}_{4}{ }^{-}$the pre-equilibrium is shifted towards the reactant complex $\mathbf{R} \mathbf{C}_{\mathbf{x}}(\mathrm{OSIP})$ and their characteristic basicity promotes the nucleophilic attack. On the other hand, anions having stronger coordination power like OTs ${ }^{-}$and TFA- slow down the reaction rate, as the pre-equilibrium is shifted to initial complex IC $\mathbf{C}_{\mathbf{x}}$ (ISIP) and the activation barrier of the nucleophile attack step is increased.

$\begin{array}{ccccc}\text { Anion } & \text { time }(\mathbf{m i n})^{\mathbf{a}} & \text { conversion }(\%)^{\mathbf{a}} & \text { TOF }\left(\mathbf{m i n}^{-1}\right)^{\mathbf{a}} & \text { activation energy }(\mathbf{k c a l} / \mathbf{m o l}) \\ \mathrm{BF}_{4}^{-} & 118 & >98 & 2.72 & 13.9 \\ \text { OTf }^{-} & 61 & >98 & 5.84 & 11.9 \\ \text { OTs }^{-} & 120 & 82 & 2.43 & 15.6 \\ \text { TFA }^{-} & 120 & 4 & 0.04 & 20.2\end{array}$

a Taken from ref. ${ }^{54}$ 
Table 1. Calculated activation energy barriers for the nucleophilic attack step of methanol to 2-butyne in the $\left[P\left({ }^{t} B u\right)_{3}-\right.$ $\mathrm{Au}-\mathrm{X}]\left(\mathrm{X}^{-}=\mathrm{BF}_{4}^{-}, \mathrm{OTf}^{-}, \mathrm{OTs}^{-}, \mathrm{TFA}^{-}\right)$catalyzed reaction and experimental TOF values for the corresponding reaction with 3-hexyne.

It's worth to mention here that in the pre-equilibrium step for the TFA- anion, a catalytically inactive tricoordinated complex $\mathbf{T C}_{\text {TFA }}$ is calculated, where the gold center coordinates to the phosphine ligand, the TFA- anion and the alkyne substrate (see Figure S3 in the Supporting information). Very interestingly, this peculiar tricoordinated species has been previously found for highly coordinating anion such as TFA- and $\mathrm{OAc}^{-}$(acetate) ${ }^{51}$ due to their behavior as bad leaving group, and even for medium coordinating ability anion like PFHp- (2,2,3,3,4,4,5,5,6,6,7,7,7-tridecafluoroheptanoate), but not for OTs ${ }^{-}$, despite the fact that its coordinating ability is close to that of $\mathrm{PFHp}^{-} .{ }^{52}$ This apparent discrepancy has been reconciled on the basis of their geometrical structures. As a matter of fact, the more "spherical" symmetry of $\mathrm{OTs}^{-}\left(-\mathrm{SO}_{3}{ }^{-}\right.$group has a tetrahedral structure and it is a "tridentate" ligand towards $\mathrm{Au}$ ) with respect to $\mathrm{PFHp}^{-}, \mathrm{TFA}^{-}$and $\mathrm{OAc}^{-}$ $\left(-\mathrm{CO}_{2}{ }^{-}\right.$is a planar and "bidentate" ligand towards $\left.\mathrm{Au}\right)$ correlates with its lower attitude to form tricoordinated species. Thus, the coordinating ability of the anion to gold may not solely correlates with its ability as leaving group in the substitution reaction by substrate, but also its geometry (more "spherical" tridentate or bidentate features) contributes to it. ${ }^{49}$ Overall, both the present and our previous results highlight the crucial role of the anion in the catalysis promoted by $[\mathrm{L}-\mathrm{Au}-\mathrm{X}]$ complexes and how this effect depends on its intrinsic properties. The above results fully corroborate our proposed mechanism reported in ref. ${ }^{51}$ for $\mathrm{L}=\mathrm{NHC}$, thus ruling out the hypothesis that OTs ${ }^{-}$could show a different ability to act as a template when $L=P\left({ }^{+} B u\right){ }_{3}$.

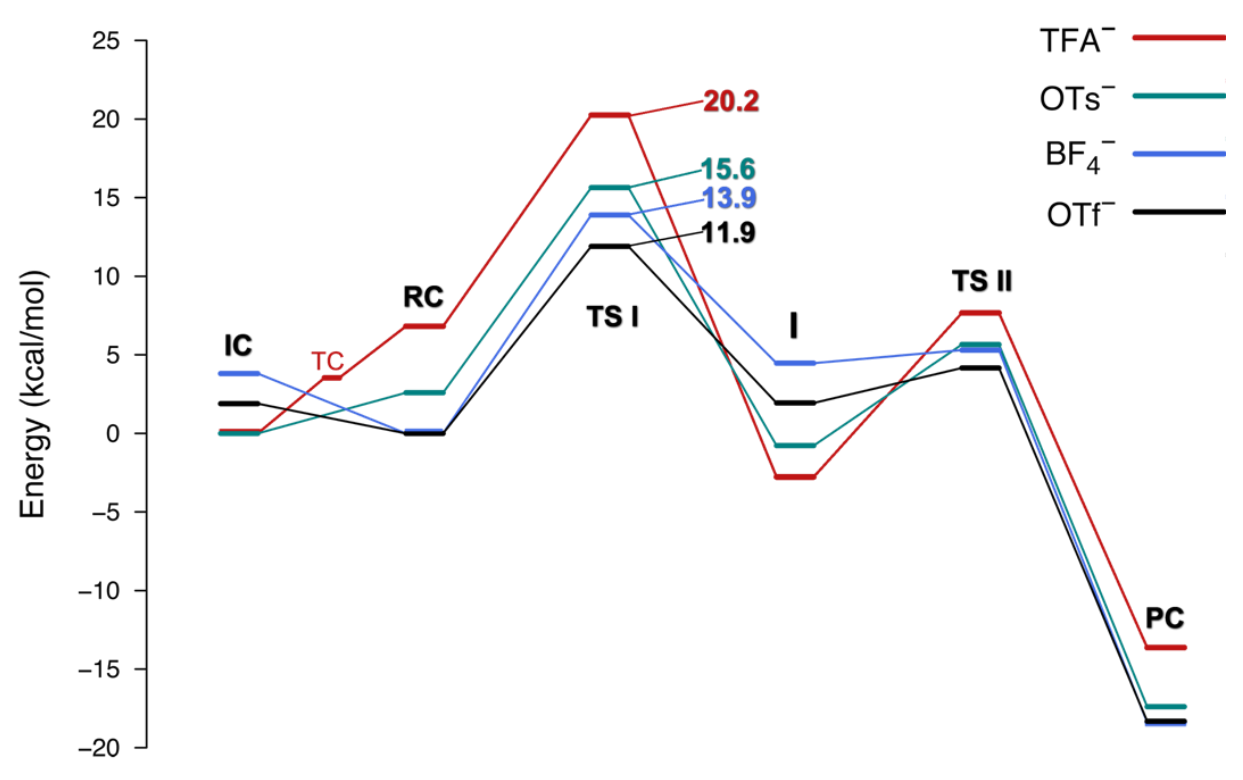

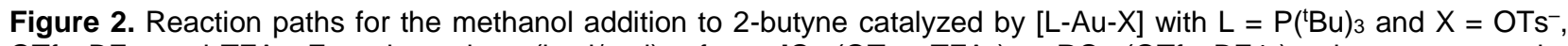
$\mathrm{OTf}^{-}, \mathrm{BF}_{4}^{-}$and TFA ${ }^{-}$. Energies values $(\mathrm{kcal} / \mathrm{mol})$ refer to $\mathbf{I C x}\left(\mathrm{OTs}^{-}, \mathrm{TFA}^{-}\right)$or $\mathbf{R C}_{\mathbf{x}}\left(\mathrm{OTf}^{-}, \mathrm{BF}^{-}\right)$, taken as zero point energy.

Next we consider the carbene-based gold catalyst, [NHC-Au-OTs], for which an experimental TOF value of $5.06 \mathrm{~min}^{-1}$ at $18 \mathrm{~min}$ and $>98 \%$ of conversion has been reported. ${ }^{54}$ By fixing the anion to OTs ${ }^{-}$we now 
study the effect of varying the ligand with $L=N H C$. The calculated initial complex IC, reactants complex RC, intermediate I, product complex PC, transition state TSI for the nucleophilic attack step and transition state TSII for the protodeauration step in the presence of the OTs ${ }^{-}$anion are shown in Figure 3. We should mention here that a very similar reaction path (both geometries and relative energies) has been calculated for this system in ref. ${ }^{51}$ (see Figure S9 in the $\mathrm{SI}$ ) using different computational details. Analogously to the phosphine ligand, the most stable species formed by the catalyst, the alkyne and the nucleophile has been calculated to be the anion-coordinated initial complex IC, which has been taken as the zero point energy. In the initial complex IC the 2-butyne is in the second coordination sphere, weakly interacting with one methyl

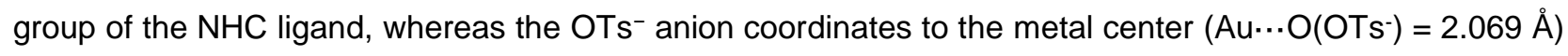
while forming a $\mathrm{HB}$ with one methanol molecule $\left(\mathrm{MeOH}_{\cdots} \mathrm{O}\left(\mathrm{OTs}^{-}\right)=1.767 \AA\right)$. The formation of the reactant complex RC from the initial complex IC is thermodynamically unfavorable by $2.7 \mathrm{kcal} / \mathrm{mol}$. In the reactant complex RC the 2-butyne substitutes the anion, which interacts through its oxygen atoms with the metal center $\left(\mathrm{Au} \cdots \mathrm{O}\left(\mathrm{OTs}^{-}\right)=3.272 \AA\right)$ and with the "bridging" methanol $\left(\mathrm{MeOH}^{-} \mathrm{O}\left(\mathrm{OTs}^{-}\right)=1.694 \AA\right)$. The nucleophilic attack of methanol from the $\mathbf{R C}$ leads to the transition state TSI with an activation energy barrier of $10.0 \mathrm{kcal} / \mathrm{mol}$. In TSI the distance of the attacking methanol from substrate C1 is $2.120 \AA$, the bond between the gold center and the $\mathrm{C} 1$ is elongated $(2.698 \AA)$, while that between the gold and the other carbon atom of the triple bond (C2) becomes shortened (2.109 $\AA$ ). The abstraction of the proton from the "bridging" methanol by OTs- leads to the consequent polarization of the oxygen atom of the nucleophilic methanol, whose $\mathrm{O}-\mathrm{H}$ bond is elongated (1.039 $\AA$ ). In the intermediate I the "bridging" methanol acts both as a proton acceptor from the nucleophile and as a proton donor to the OTs- anion. For the protodeauration, in TSII the proton transfer from OTs ${ }^{-}$towards C2 is analogously mediated by the "bridging" methanol. The energy barrier for this step is calculated to be $5.2 \mathrm{kcal} / \mathrm{mol}$. In the final product complex PC the hydrogen is in trans position with respect to methoxy and the gold center coordinates to the product via its unsaturated double bond and it weakly interacts with the anion. The product complex PC is stabilized with respect to intermediate I by $19.6 \mathrm{kcal} / \mathrm{mol}$, while the overall reaction from $\mathbf{I C}$ to $\mathbf{P C}$ is exothermic by $22.1 \mathrm{kcal} / \mathrm{mol}$ with an activation energy barrier of $10.0 \mathrm{kcal} / \mathrm{mol}$. 


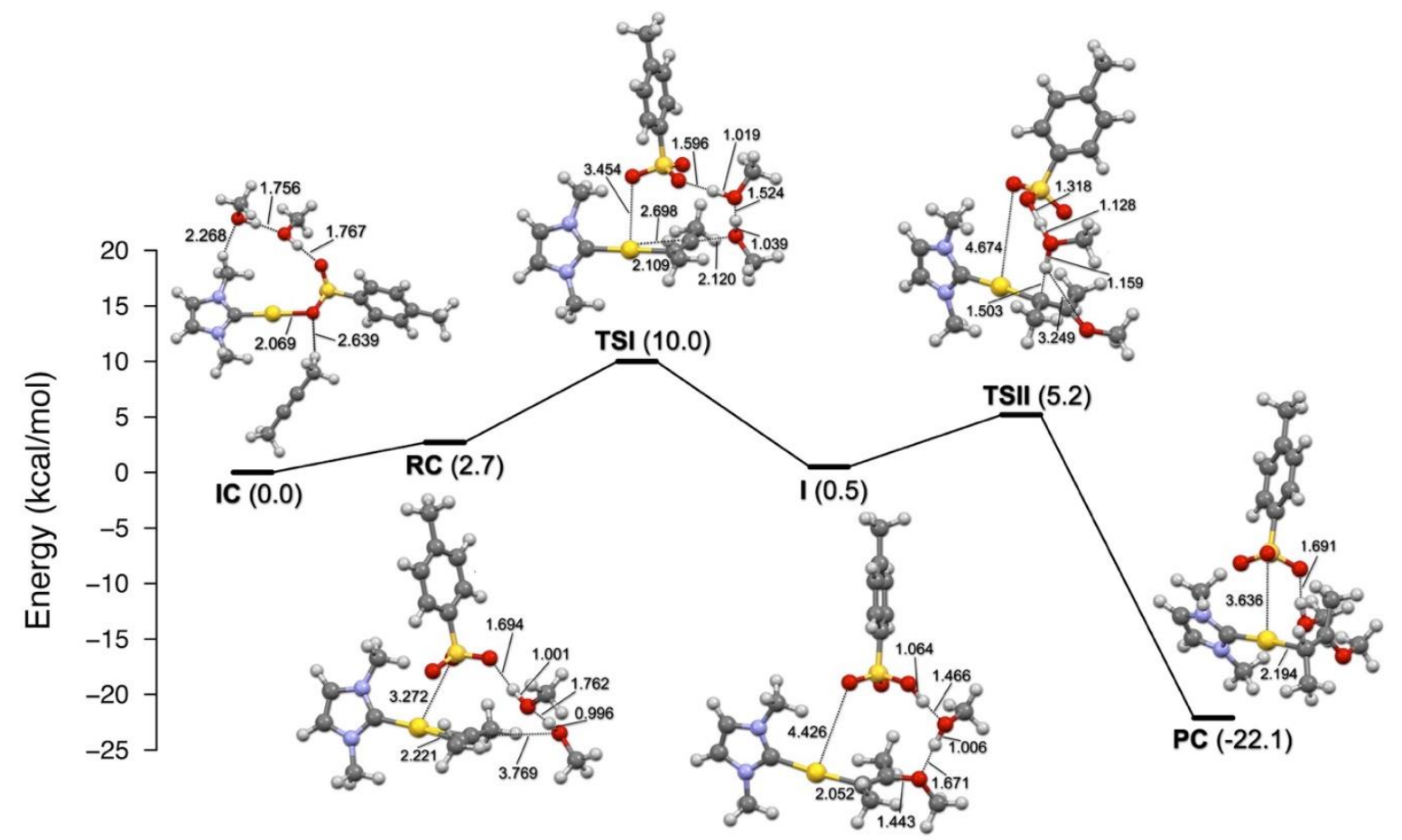

Figure 3. Reaction path for the methanol addition to 2-butyne catalyzed by [L-Au-X] with $L=N H C$ and $X=O T s^{-}$. Initial complex IC, reactants complex RC, intermediate I, product complex PC, transition state TSI for the nucleophilic attack step and TSII for the protodeauration step are shown. Energies values $(\mathrm{kcal} / \mathrm{mol})$ refer to IC, taken as zero point energy. Bond lengths are in angstroms.

The calculated activation energy barriers for the two [L-Au-OTs] catalysts very nicely agree with the experimentally observed catalytic efficiency $\left(L=N H C>L=P\left({ }^{t} B u\right)_{3}\right)$. This result is somewhat counterintuitive, on the basis of the common knowledge that a poor electron donor such as a phosphine enhances the acidity of the metal fragment, resulting in a greater electron-withdrawing ability when the substrate is coordinated. On the other hand, since NHC is considered a stronger electron donor, the metal fragment $[\mathrm{L}-\mathrm{Au}]^{+}$should be less acidic and should not deplete the charge on the unsaturated substrate bond as much. ${ }^{19}$ However, this picture has been recently questioned. The ligand ability to donate electron density to gold has been quantified by some of us in a series of [L-Au-(CO) $]^{+/ 0}$ complexes. ${ }^{76}$ In particular, this study reveals that phosphine ligands actually donate much more electronic density to gold than carbene ligands, even if only a part of this donation can be transmitted to the ligand in trans position. Such unconventional result calls us for a re-evaluation of the $\mathrm{P}\left({ }^{\mathrm{B}} \mathrm{Bu}\right)_{3} / \mathrm{NHC}$ electron withdrawing effect in our [ $\mathrm{L}-$ $\mathrm{Au}-\mathrm{X}]$ systems when the trans ligand is the 2-butyne substrate through the Charge-Displacement analysis, both in the presence and without the OTs- anion.

\section{Combined Anion/Ligand Effect}

As a first step to study the combined anion/ligand effect, it is instructive to directly compare the reaction profiles obtained for the $\left[\mathrm{P}\left({ }^{\mathrm{B}} \mathrm{Bu}\right)_{3}-\mathrm{Au}-\mathrm{OTs}\right]$ and $[\mathrm{NHC}-\mathrm{Au}-\mathrm{OTs}]$ catalysts (Figure 4). 


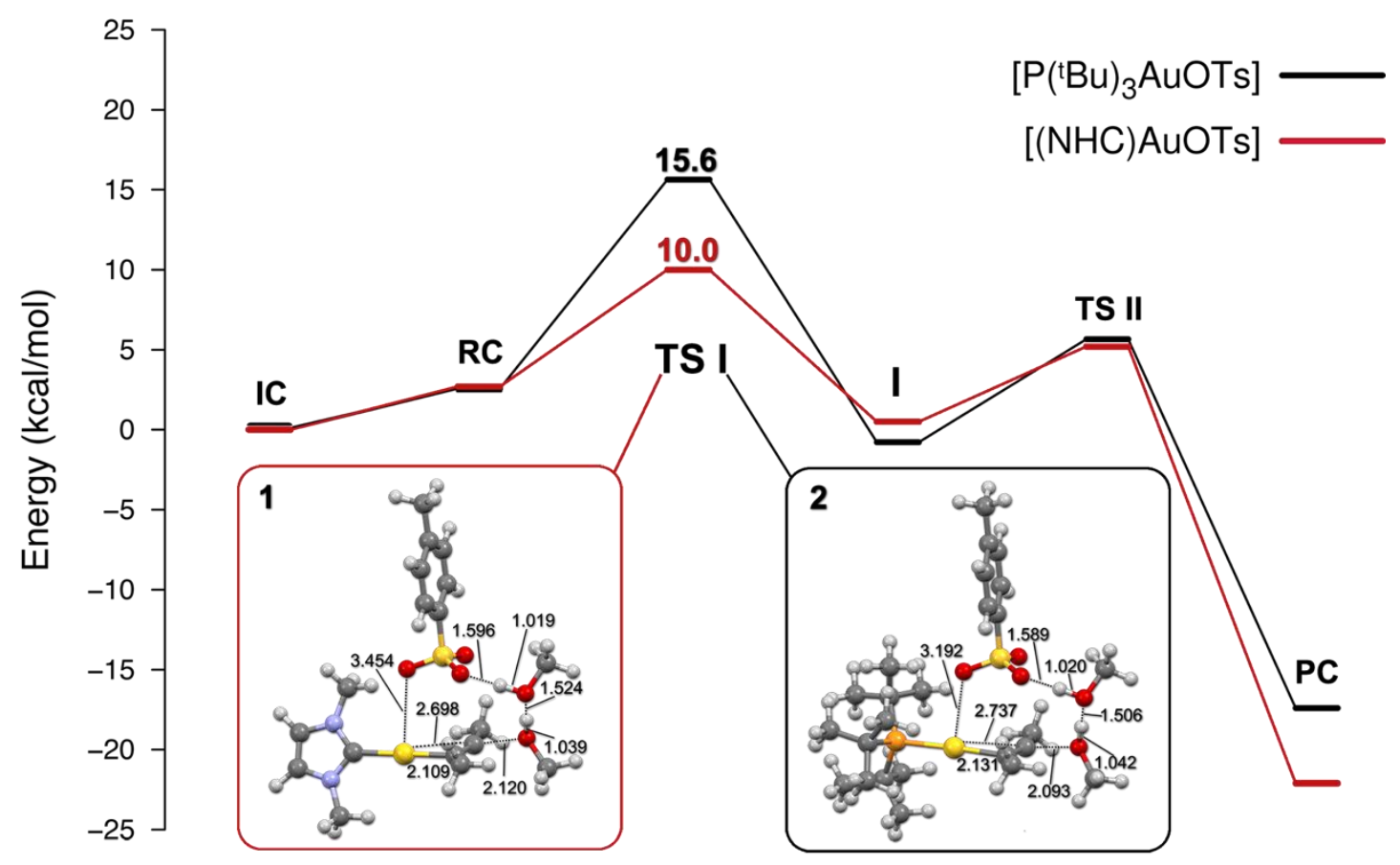

Figure 4. Reaction paths for the methanol addition to 2-butyne with $\mathrm{L}=\mathrm{P}\left({ }^{\mathrm{t}} \mathrm{Bu}\right)_{3}, \mathrm{NHC}$ and $X=\mathrm{OTs} \mathrm{s}^{-}$. Energies values $(\mathrm{kcal} / \mathrm{mol}$ ) refer to IC, taken as zero point energy. In the two boxes the transition states geometrical structures (distance in angstroms) for the two [L-Au-OTs] complexes are shown.

We can see that the pre-equilibrium as well as the protodeauration step are very similar, whereas the main difference arises in the RDS of the reaction, which accounts for the different TOF values, as expected. The energy of the transition state configuration for the nucleophilic attack step is the most important parameter for our discussion because it is directly related to the activity of the catalyst and to the electrophilicity of the carbon interacting with methanol. Therefore, we can consider the energy of the transition state as a (inverse) measure of the activation of the CC triple bond. Moreover, it is now widely accepted that slippage of the [L-M] fragment along the axis of the bound alkyne accompanies its activation. ${ }^{77}$ The above result is consistent with the increased electrophilicity expected upon $\eta^{2} \rightarrow \eta^{1}$ deformation, ${ }^{78}$ which in turn enhances the charge subtracted from the triple bond region. ${ }^{79}$ The partial slippage away from the symmetrical $\eta^{2}$ coordination in the transition state facilitates charge transfer from the nucleophile to the distorted $\pi$ system and, in particular, to the carbon atom $\mathrm{C} 1$ farther away from gold. Therefore, the Au-C1 bond distance can also be related to the nucleophilic attack activation barrier, or in other words it can be considered a reactivity index. To gain more in-depth information, we compare the reactant complex $\mathbf{R C}$ and transition state TSI [(L-Au-S)OTs] geometrical structures $\left(\mathrm{L}=\mathrm{P}\left({ }^{\mathrm{t}} \mathrm{Bu}\right)_{3}, \mathrm{NHC}\right.$ and $\mathrm{S}=2$-butyne) with the corresponding anion-free [L-Au-S]+ optimized structures. 


\begin{tabular}{|c|c|c|c|c|c|}
\hline $\mathbf{L}$ & [L-Au-S $]^{+}$ & RC [(L-Au-S)OTs $]$ & $\Delta(\mathrm{Au}-\mathrm{C} 1)$ & TSI [(L-Au-S)OTs] & $\Delta(\mathrm{Au}-\mathrm{C} 1)$ \\
\hline $\mathrm{P}\left({ }^{\mathrm{t}} \mathrm{Bu}\right)_{3}$ & $\begin{array}{l}\mathrm{Au}-\mathrm{C} 1=2.272 \\
\mathrm{Au}-\mathrm{C} 2=2.272\end{array}$ & $\begin{array}{l}\mathrm{Au}-\mathrm{C} 1=2.273 \\
\mathrm{Au}-\mathrm{C} 2=2.256 \\
\mathrm{Au}-\mathrm{OT} \mathrm{s}=3.221\end{array}$ & 0.001 & $\begin{array}{l}\mathrm{Au}-\mathrm{C} 1=2.737 \\
\mathrm{Au}-\mathrm{C} 2=2.131 \\
\mathrm{Au}-\mathrm{OTs}=3.192\end{array}$ & 0.465 \\
\hline NHC & $\begin{array}{l}\mathrm{Au}-\mathrm{C} 1=2.225 \\
\mathrm{Au}-\mathrm{C} 2=2.225\end{array}$ & $\begin{array}{l}\mathrm{Au}-\mathrm{C} 1=2.231 \\
\mathrm{Au}-\mathrm{C} 2=2.221 \\
\text { Au-OTs }=3.272\end{array}$ & 0.006 & $\begin{array}{l}\text { Au-C1 }=2.698 \\
\text { Au-C2 }=2.109 \\
\text { Au-OTs }=3.454\end{array}$ & 0.473 \\
\hline
\end{tabular}

Table 2. Au-S and Au-OTs bond distances (in angstroms) for the optimized anion-free [L-Au-S ${ }^{+}$, reactant complex RC [(L-Au-S)OTs] and transition state for the nucleophilic attack step TSI [(L-Au-S)OTs] species $\left(\mathrm{L}=\mathrm{P}\left({ }^{\mathrm{t}} \mathrm{Bu}\right)_{3}, \mathrm{NHC}\right.$ and $\mathrm{S}=$ 2-butyne). $\Delta(\mathrm{Au}-\mathrm{C} 1)$ refers to the Au-C1 bond distance increase with respect to the value in the corresponding [L-Au$\mathrm{S}]^{+}$complex.

From Table 2, we see that both the anion-free $[\mathrm{L}-\mathrm{Au}-\mathrm{S}]^{+}$complexes are in their equilibrium symmetrical $\eta^{2}$ substrate coordination, with Au-C1=Au-C2 $=2.225 \AA$ in $[\mathrm{NHC}-\mathrm{Au}-\mathrm{S}]^{+}$and $\mathrm{Au}-\mathrm{C} 1=\mathrm{Au}-\mathrm{C} 2=2.272 \AA$ in $\left[\mathrm{P}\left({ }^{\mathrm{t}} \mathrm{Bu}\right)_{3^{-}}\right.$ $\mathrm{Au}-\mathrm{S}]^{+}$. A certain asymmetry of the coordinated 2-butyne can be found by including the OTs- anion in both the $\mathrm{RC}$ [(L-Au-S)OTs] complexes, where the Au-C1 bond distance slightly increases by $0.001 \AA$ in $R C$ $\left[\left(\mathrm{P}\left({ }^{\mathrm{t}} \mathrm{Bu}\right)_{3}-\mathrm{Au}-\mathrm{S}\right) \mathrm{OTs}\right]$ and by $0.006 \AA$ in $\mathrm{RC}[(\mathrm{NHC}-\mathrm{Au}-\mathrm{S}) \mathrm{OTs}]$ with respect to the anion-free corresponding

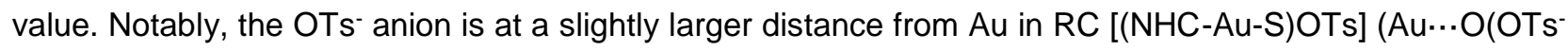
) $=3.272 \AA$ ) than in $\mathrm{RC}\left[\left(\mathrm{P}\left({ }^{\mathrm{t} B u}\right)_{3}-\mathrm{Au}-\mathrm{S}\right) \mathrm{OTs}\right]\left(\mathrm{Au} \cdots \mathrm{O}\left(\mathrm{OTs}^{-}\right)=3.221 \AA\right.$ ). This finding suggests a counterion OTs- effect on the substrate activation in $\mathrm{RC}\left[\left(\mathrm{P}\left({ }^{(} \mathrm{Bu}\right)_{3}-\mathrm{Au}-\mathrm{S}\right) \mathrm{OTs}\right]$ complex, where the higher OTs' affinity towards the cationic $\left[\mathrm{P}\left({ }^{(} \mathrm{Bu}\right)_{3}-\mathrm{Au}\right]^{+}$fragment makes the 2-butyne slippage more difficult. Looking at the two transition states for the nucleophilic attack step, TSI [(NHC-Au-S)OTs] and TSI [( $\left.\left.\left({ }^{(}{ }^{\mathrm{B} u}\right)_{3}-\mathrm{Au}-\mathrm{S}\right) \mathrm{OTs}\right]$, even more pronounced structural differences can be observed: i) the OTs anion is a sizable larger distance

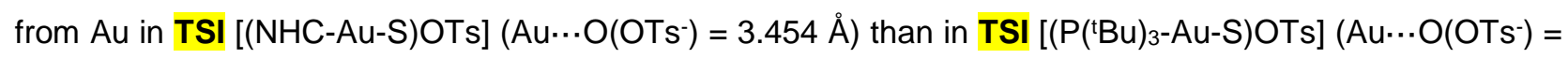
$3.192 \AA$ ), and ii) the 2-butyne slippage away from the symmetrical $\eta^{2}$ coordination is overall enhanced, but again it is smaller in TSI [(P( $\left.\left.\left.{ }^{(} \mathrm{Bu}\right)_{3}-\mathrm{Au}-\mathrm{S}\right) \mathrm{OTs}\right]$ than in TSI [(NHC-Au-S)OTs] (see Table 2). This result is in agreement with experimental observations which indicate that OTs- tends to re-enter gradually in the first coordination sphere of gold in the $\left[\left(\mathrm{P}\left({ }^{\mathrm{t}} \mathrm{Bu}\right)_{3}-\mathrm{Au}-\mathrm{S}\right) \mathrm{OTs}\right]$ system while the reaction proceeds. ${ }^{54}$ When phosphane rather than $\mathrm{NHC}$ are bound to gold, the OTs- affinity to cationic [L-Au] $]^{+}$fragment is higher. The smaller $\eta^{2} \rightarrow \eta^{1}$ deformation induced by the OTs" anion coordination in TSI [( $\left.\left.\left({ }^{(} \mathrm{B} B\right)_{3}-\mathrm{Au}-\mathrm{S}\right) \mathrm{OTs}\right]$, which we can estimate by $\Delta(\mathrm{Au}-\mathrm{C} 1)=0.465 \AA$ and compare to that in TSI [(NHC-Au-S)OTs], $\Delta(\mathrm{Au}-\mathrm{C} 1)=0.473 \AA$, should be responsible for a decreasing of the charge subtracted from the substrate region in this transition state consistently with the higher corresponding activation energy and in agreement with the experimental findings. ${ }^{54}$ Notwithstanding, it is rather difficult to rationalize the different catalytic activity only by considering the geometrical structure of the complexes.

For this purpose we decided to perform the Charge-Displacement analysis in the two transition states TSI $\left[\left(\mathrm{P}\left({ }^{(} \mathrm{Bu}\right)_{3}-\mathrm{Au}-\mathrm{S}\right) \mathrm{OTs}\right]$ and TSI [(NHC-Au-S)OTs] where, for simplicity, the two methanol molecules have been removed and in the corresponding anion-free $\left[\mathrm{P}\left({ }^{\mathrm{t}} \mathrm{Bu}\right)_{3}-\mathrm{Au}-\mathrm{S}\right]^{+}$and $[\mathrm{NHC}-\mathrm{Au}-\mathrm{S}]^{+}$optimized structures for comparison. The aim is to obtain a quantitative assessment of the substrate multiple bond activation by the $[\mathrm{L}-\mathrm{Au}]^{+}$fragment with and without the presence of the anion. 
In Figure 5 the three-dimensional contour plots of the electron density difference $\Delta \rho(x, y, z)$ between the density of the selected complexes TSI [(L-Au-S)OTs], [L-Au-S $]^{+}\left(\mathrm{L}=\mathrm{P}\left({ }^{\mathrm{B}} \mathrm{Bu}\right)_{3}, \mathrm{NHC}\right)$ and that of their corresponding constituting fragments are depicted (see Methodology section). The defined fragments in the present study are $[\mathrm{L}-\mathrm{Au}]^{+}$and the alkyne substrate $\mathbf{S}\left(\right.$ for $\left[\mathrm{P}\left({ }^{+} \mathrm{Bu}\right)_{3}-\mathrm{Au}-\mathrm{S}\right]^{+}$and $\left.[\mathrm{NHC}-\mathrm{Au}-\mathrm{S}]^{+}\right)$or $[\mathrm{L}-\mathrm{Au}]^{+}$and the [S-OTs-] moiety in the case of the transition state structures (for TSI [(P('Bu) $\left.{ }_{3}-\mathrm{Au}-\mathrm{S}\right) \mathrm{OTs}$ ] and TSI [(NHC-Au-S)OTs]). Figure 5 clearly shows that, upon coordination to gold, the triple bond of the alkyne in both the transition states TSI $\left[\left(\mathrm{P}\left({ }^{\mathrm{B}} \mathrm{Bu}\right)_{3}-\mathrm{Au}-\mathrm{S}\right) \mathrm{OTs}\right]$ and TSI [(NHC-Au-S)OTs] is strongly polarized towards the gold site. In particular, we notice accumulation of electron density on the $\mathrm{C} 2$ region, especially along the C2-Au bond, and a pronounced depletion of charge on $\mathrm{C} 1$ atom at the outer region of the C1-Au bond, which is responsible for the electrophilic character of $\mathrm{C} 1$ that makes it susceptible to the nucleophilic attack. The alkyne triple bond is also activated in the corresponding anion-free structures $\left[\mathrm{P}\left({ }^{\mathrm{t}} \mathrm{Bu}\right)_{3}-\mathrm{Au}-\mathrm{S}\right]^{+}$and [NHC-Au-S]+ but to a lesser extent: accumulation of electron density is observed in the region at about the midpoint of the Au-C1C2 bond, whereas a symmetric charge depletion is seen close to the $\mathrm{C} 1 \mathrm{C} 2$ bond, both at the inner and the outer regions of the Au-C1C2 bond.
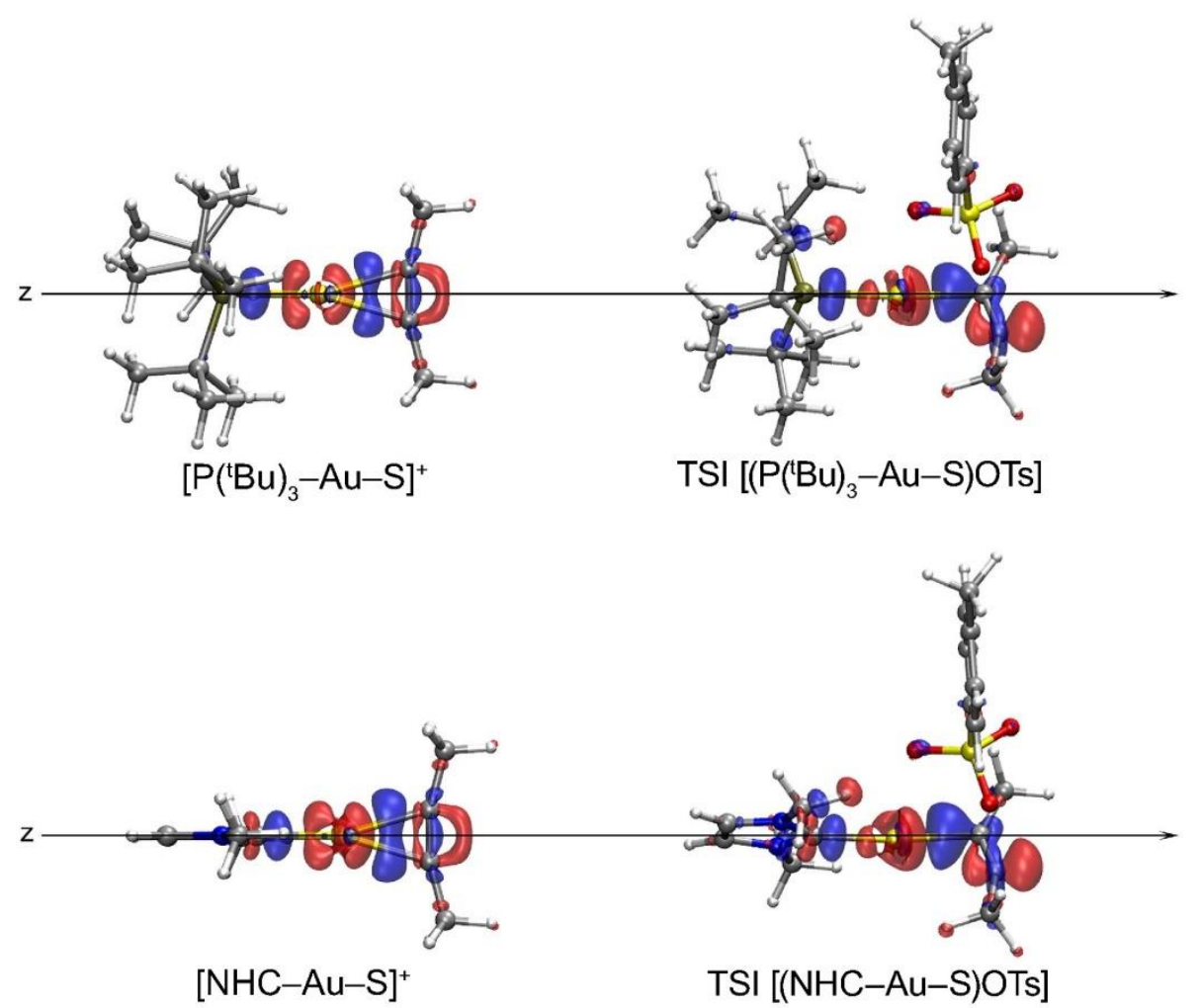

Figure 5. Isodensity surfaces plots $\left( \pm 0.005\right.$ e a.u. $\left.{ }^{-3}\right)$ of the $\Delta \rho$ for the Au-S bond in complexes TSI [(L-Au-S)OTs], [LAu-S $]^{+}\left(\mathrm{L}=\mathrm{P}\left({ }^{\mathrm{t}} \mathrm{Bu}\right)_{3}\right.$, upper panel, $\mathrm{NHC}$, lower panel). The black arrows represent the z-axis of integration for the $\mathrm{CD}$ functions. Red surfaces indicate charge depletion regions, blue surfaces identify charge accumulation regions.

In order to give a quantitative measure of the net charge that has moved away from the alkyne, we integrated $\Delta q$ across the $\mathrm{z}$ axis, which was chosen to pass through the Au atom and the middle of the substrate $\mathrm{C}-\mathrm{C}$ bond for [L-Au-S]+ complexes, and through the Au and the $\mathrm{C} 2$ atom for TSI [(L-Au-S)OTs] ones. In all cases, the 2-butyne substrate carbon atoms are located at the origin of the reference system and the $[\mathrm{L}-\mathrm{Au}]^{+}$fragments lie on the negative $\mathrm{z}$ region. Figure 6 shows the CD curves (see Equation 1 ) for the selected complexes. 


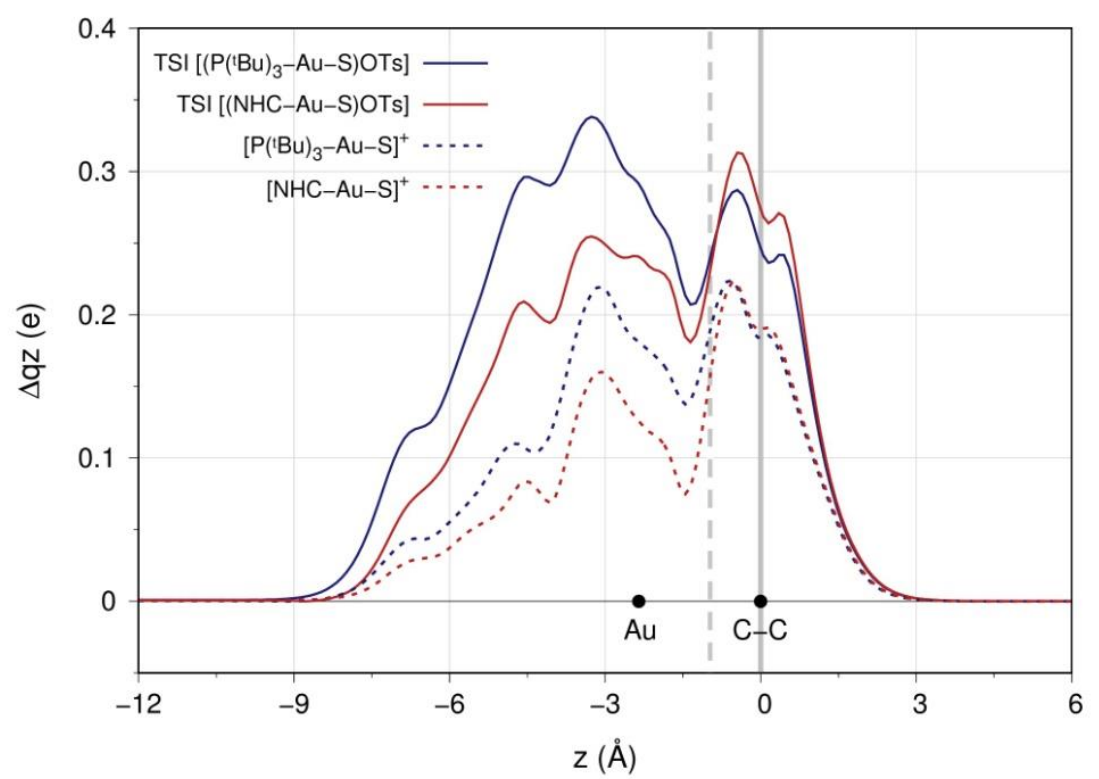

Figure 6. CD curves for complexes [L-Au-S $]^{+}$, TSI $[(\mathrm{L}-\mathrm{Au}-\mathrm{S}) \mathrm{OTs}]\left(\mathrm{L}=\mathrm{P}\left({ }^{\mathrm{t}} \mathrm{Bu}\right)_{3}, \mathrm{NHC}\right)$. Black dots indicate the $z$ position of the atomic nuclei (Au and substrate CC). Solid curves represent the TSI [(L-Au-S)OTs] complexes (TSI [(NHC-Au-

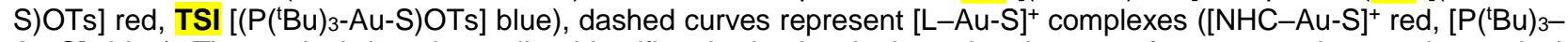
$\mathrm{Au}-\mathrm{S}]^{+}$blue). The vertical dotted gray line identifies the isodensity boundary between fragments, whereas the vertical solid grey line identifies the middle of the substrate $\mathrm{C}-\mathrm{C}$ bond for $[\mathrm{L}-\mathrm{Au}-\mathrm{S}]^{+}$, and the $\mathrm{C} 2$ atom position for TSI [(L-AuS)OTs] complexes.

All of the four curves are positive through the overall complex region, describing a flow of electron charge from the right (substrate region) to the left ([L-Au] $]^{+}$moiety region). In the left region with respect to the isodensity boundary (vertical dotted gray line, see Methodology section for definition) the curves for the phosphine compounds $\left[\mathrm{P}\left({ }^{\mathrm{t}} \mathrm{Bu}\right)_{3}-\mathrm{Au}-\mathrm{S}\right]^{+}$and $\mathrm{TSI}\left[\left(\mathrm{P}\left({ }^{\mathrm{B}} \mathrm{Bu}\right)_{3}-\mathrm{Au}-\mathrm{S}\right) \mathrm{OTs}\right]$ are more positive than those for the corresponding carbene complexes [NHC-Au-S] ${ }^{+}$and TSI [(NHC-Au-S)OTs]. In the right region an opposite behavior is observed, particularly for TSI [(L-Au-S)OTs] complexes, with the curve for carbene becoming more positive than that for phosphine compound. In the absence of the anion, at the isodensity boundary, the phosphine-metal fragment $\left[\mathrm{P}\left({ }^{\mathrm{B}} \mathrm{Bu}\right)_{3}-\mathrm{Au}\right]^{+}$is more acidic, with a total of 0.181 e flowing in the $\mathrm{S} \rightarrow$ $\left[\mathrm{P}\left({ }^{\mathrm{B}} \mathrm{Bu}\right)_{3}-\mathrm{Au}\right]^{+}$direction with respect to the carbene-based [NHC-Au$]^{+}$moiety, with only $0.148 \mathrm{e}$ that are subtracted from the substrate region upon bond formation (see Charge Transfer CTIso values in Table 3 for the anion-free complexes $\left[\mathrm{P}\left({ }^{(} \mathrm{Bu}\right)_{3}-\mathrm{Au}-\mathrm{S}\right]^{+}$and $[\mathrm{NHC}-\mathrm{Au}-\mathrm{S}]^{+}$, respectively). If we now consider the inclusion of the anion, namely the two transition states, the difference in terms of $C T_{\text {iso }}$ becomes less pronounced (0.239e and 0.229e for complexes TSI [(P( $\left.\left.\left.{ }^{\mathrm{B} B u}\right)_{3}-\mathrm{Au}-\mathrm{S}\right) \mathrm{OTs}\right]$ and TSI [(NHC-Au-S)OTs], respectively). 


\begin{tabular}{|c|c|c|}
\hline Complex & $\mathrm{CT}_{\text {ISO }}$ & $\mathbf{C T}_{c c}$ \\
\hline$\left[\mathrm{P}\left({ }^{\mathrm{t}} \mathrm{Bu}\right)_{3}-\mathrm{Au}-\mathrm{S}\right]^{+}$ & 0.181 & 0.185 \\
\hline 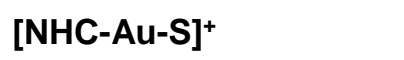 & 0.148 & 0.190 \\
\hline $\mathrm{TSI}\left[\left(\mathrm{P}\left({ }^{\mathrm{t}} \mathrm{Bu}\right)_{3}-\mathrm{Au}-\mathrm{S}\right) \mathrm{OTs}\right]$ & 0.239 & 0.24 \\
\hline TSI [(NHC-Au-S)OTs] & 0.229 & 0.27 \\
\hline
\end{tabular}

Table 3. $C D$ function values taken at the isodensity boundary (Charge Transfer $C_{\text {ISO }}$ ) and at the carbon position

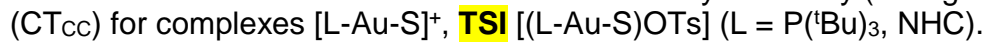

Although, quite interestingly, a certain degree of anion/ligand interplay can be already highlighted in this finding, where the $\left[\mathrm{P}\left({ }^{+} \mathrm{Bu}\right)_{3}-\mathrm{Au}\right]^{+}$higher withdrawing ability at the isodensity boundary is partially counteracted by the closer localization of the anion around the gold, so far the results are still not able to rationalize the experimental catalytic activities of $\left[\left(\mathrm{P}\left({ }^{\mathrm{B}} \mathrm{Bu}\right)_{3}-\mathrm{Au}-\mathrm{S}\right) \mathrm{OTs}\right]$ and $[(\mathrm{NHC}-\mathrm{Au}-\mathrm{S}) \mathrm{OTs}]$.

We recently found that the efficiency of the nuclephilic attack on the triple bond is driven by the amount of electronic charge subtracted from the region of the triple bond, which can be evaluated by considering the $C D$ values at the carbon atom positions ${ }^{80}$ (Charge Transfer CTcc values, see Table 3). We can see that, in the absence of the anion, we find almost the same value of $\mathrm{CT}_{\mathrm{CC}}$ in both the anion-free complexes [NHC$\mathrm{Au}-\mathrm{S}]^{+}$and $\left[\mathrm{P}\left({ }^{\mathrm{B}} \mathrm{Bu}\right)_{3}-\mathrm{Au}-\mathrm{S}\right]^{+}(0.190 \mathrm{e}$ and $0.185 \mathrm{e}$, respectively), suggesting that the electronic effect of the $\mathrm{P}\left({ }^{\mathrm{t}} \mathrm{Bu}\right)_{3}$ and $\mathrm{NHC}$ ligands at the substrate region is surprisingly very similar. On the other hand, in the transition states, and therefore in the presence of the anion, the value of CTcc in complex TSI [(NHC-AuS)OTs] is higher compared to that in TSI [(P(tBu $\left.\left.)_{3}-A u-S\right) O T s\right] \quad(0.274 \mathrm{e}$ vs. $0.246 \mathrm{e}$, respectively). These values are in perfect agreement with the experimental fact that [(NHC)Au-OTs] is a faster catalyst than $\left[\left(\mathrm{P}\left({ }^{\mathrm{B}} \mathrm{Bu}\right)_{3}-\mathrm{Au}-\mathrm{OTs}\right]\right.$, giving us an elegant framework to rationalize the ligand effect.

The result that the counterion affinity, which in turn depends on the $[\mathrm{L}-\mathrm{Au}]^{+}$fragment, influences the nucleophilic attack activation barrier through the modulation of the $\eta^{2} \rightarrow \eta^{1}$ substrate deformation and thus the electrophilicity of the alkyne clearly explains the anion/ligand correlation in the $\left[\mathrm{P}\left({ }^{\mathrm{t}} \mathrm{Bu}\right)_{3}-\mathrm{Au}-\mathrm{OTs}\right]$ and [NHC-Au-OTs] catalysts. If the net Lewis acidity of the $[\mathrm{L}-\mathrm{Au}]^{+}$fragment was the sole and unique feature responsible for alkyne activation, we would be at a loss to explain the different catalytic performances. Our study demonstrates that the anion can modulate such a Lewis acidity by its position, which is dictated by the steric properties of $L$. The $C D$ analysis revealed to be a powerful tool capable of taking into account the anion and the ligand effect together and to unravel their interplay in the RDS of the reaction.

All the findings in our mechanistic study and CD analysis are perfectly consistent with the experimental data, and within our interpretative framework, we can rationalize the activity trend of the $[\mathrm{L}-\mathrm{Au}-\mathrm{X}]$ catalyst $\left(\mathrm{OTf}^{-}>\mathrm{BF}_{4^{-}}>\mathrm{OTs^{- }}>\mathrm{TFA}\right)$ when the ligand $\mathrm{L}$ is $\mathrm{P}\left({ }^{\mathrm{t}} \mathrm{Bu}\right)_{3}$ and, nontrivially, the better catalytic performance of $\mathrm{NHC}$ with respect to $\mathrm{P}\left({ }^{\mathrm{t}} \mathrm{Bu}\right)_{3}$ when the anion is fixed to OTs ${ }^{-}$. 


\section{Conclusions}

We have carried out DFT calculations and Charge-Displacement (CD) analysis to investigate the anion/ligand interplay in the reaction mechanism of alkoxylation of alkynes promoted by a series of [L-Au-X] $\left(\mathrm{L}=\mathrm{NHC}, \mathrm{P}\left({ }^{\mathrm{t}} \mathrm{Bu}\right)_{3}\right.$ and $\left.\mathrm{X}=\mathrm{OTs}^{-}, \mathrm{OTf}^{-}, \mathrm{BF}^{-}, \mathrm{TFA}^{-}\right)$compounds. The experimental catalytic efficiency trend shows that the choice of the anion $X^{-}$to achieve the best performance for a given $[L-A u-X]$ catalyst strongly depends on the nature of the ligand $L$ and viceversa. ${ }^{54}$ In the case of complexes bearing phosphanes, the intermediate to low coordination power and weak basicity of the OTf- anion provide the best compromise to obtain an efficient catalysis in the methoxylation of 3-hexyne. On the other hand, for NHC compounds a different behaviour has been observed, and the top choice is represented by the intermediate to high coordination abilities and relatively high basicity of $\mathrm{OTs}^{-}$. In particular, the best settings have been found to be $\mathrm{P}\left({ }^{(} \mathrm{Bu}\right)_{3} / \mathrm{OTf}$ and $\mathrm{NHC} / \mathrm{OTs}$. Focusing on $\left[\mathrm{P}\left({ }^{\mathrm{t}} \mathrm{Bu}\right)_{3}-\mathrm{Au}-\mathrm{X}\right]$ catalyst, we have first demonstrated that the counterion effect in the reaction mechanisms can be predicted on the basis of its expected coordinating ability/proton acceptor property and of the geometry of its anchoring group similarly to what we found for the [NHC-Au-OTs] catalyst. ${ }^{50-52}$ In particular, in the nucleophilic attack step, the anion acts as a template, holding the nucleophile at the right position for the outer sphere attack to the substrate and as a hydrogen-bond acceptor, enhancing the nucleophilicity of the attacking alcohol. Instead, on comparing the $\mathrm{NHC} / \mathrm{OTs}^{-}$and $\mathrm{P}\left({ }^{\mathrm{t}} \mathrm{Bu}\right)_{3} / \mathrm{OTs}^{-}$reaction mechanisms, we found that the different observed catalytic behavior relies on the activation energy barrier of the nucleophilic attack (the RDS) step. We then investigated, through the Charge-Displacement analysis, the activation of the unsaturated hydrocarbon multiple bond (alkyne) by the $[\mathrm{L}-\mathrm{Au}]^{+}\left(\mathrm{L}=\mathrm{NHC}, \mathrm{P}\left({ }^{\mathrm{t} B u}\right)_{3}\right)$ fragment, providing a quantitative measure of the electronic charge subtracted from the substrate region where the nucleophilic attack occurs, both in the presence and without the OTs anion. This analysis represents a key tool for the interpretation and rationalization of the experimental findings which allowed to unravel the anion/ligand combined role.

The interplay between the anion and the ligand has been shown to be crucial in modulating the electrophilicity of the alkyne substrate: i) without the anion, the $\mathrm{NHC}$ and $\mathrm{P}\left({ }^{\mathrm{t}} \mathrm{Bu}\right)_{3}$ substrate activation ability is very similar, as shown by almost the same amount of electron charge removed from the nucleophilic attack site, quantified at the outer region of the $\mathrm{CC}$ bond; ii) on the other hand, the $[\mathrm{L}-\mathrm{Au}]^{+}$-anion interaction exerts an effect at the transition state of the nucleophilic attack step, since if the OTs anion is closer, the gold is less prone to accept electronic density from the alkyne, making the $\eta^{2} \rightarrow \eta^{1}$ deformation more difficult and, consequently, reducing the electrophilicity of the alkyne, as in the case of $L=P\left({ }^{t} B u\right)_{3}$. The activation provided by the electron withdrawing ability, even at the outer region of the $\mathrm{CC}$ bond, of the sole ligand is not the only factor to be taken into account to rationalize the experimental findings but also the anion interaction with the cationic metal fragment at the transition state for the nucleophilic attack contributes to it, counteracting the ligand effect. 


\section{Acknowledgements}

This work was supported by the MIUR FIRB-Futuro-in-Ricerca project RBFR1022UQ ["Novel Au(I)-based molecular catalysts: from know-how to know-why (AuCat)"]

\section{Notes and references}

1 A.S.K. Hashmi, Chem. Rev., 2007, 107, 3180-3211.

2 M. Bandini, Chem. Soc. Rev., 2011, 40, 1358-1367.

3 T.C. Boorman and I. Larrosa, Chem. Soc. Rev., 2011, 40, 1910-1925.

4 A. Corma, A. Leyva-Pérez and M. Sabater, J. Chem.Rev., 2011, 111, 1657-1712.

5 A. Leyva-Pérez and A. Corma, Angew. Chem. Int. Ed., 2012, 51, 614-635.

6 M. Rudolph and A.S.K. Hashmi, Chem. Soc. Rev., 2012, 41, 2448-2462.

7 D. Garayalde and C. Nevado, ACS Catal., 2012, 2, 1462-1479.

8 C. Obradors and A.M. Echavarren, Chem. Commun., 2014, 50, 16-28.

9 Y.-M. Wang, A.D. Lackner and F.D. Toste, Acc. Chem. Res., 2014, 47, 889-901.

10 A. S. K. Hashmi, Acc. Chem. Res., 2014, 47, 864-876.

11 H.-S. Yeom and S. Shin, Acc. Chem. Res., 2014, 47, 966-977.

12 L. Zhang, Acc. Chem. Res., 2014, 47, 877-888.

13 D. Qian and J. Zhang, Chem. Soc. Rev., 2015, 44, 677-698.

14 R. Dorel and A.M. Echavarren, Chem. Rev., 2015, 115, 9028-9072.

15 D. Pflästerer and A.S.K. Hashmi, Chem. Soc. Rev., 2016, 45, 1331-1367.

16 A. Zhdanko and M.E. Maier, Chem. Eur. J., 2014, 20, 1918-1930.

17 D.J. Gorin, F. Sherry and F.D. Toste, Chem. Rev., 2008, 108, 3351.

18 A. Fürstner and P.W. Davies, Angew. Chem. Int. Ed., 2007, 46, 3410-3449.

19 D. Malhotra, G.B. Hammond and B. Xu, Top. Curr. Chem., 2015, 357, 1-24 in Slaughter, LeGrande M., ed. Homogeneous gold catalysis. Vol. 357. Springer, 2015. 
20 W. Wang, G.B. Hammond and B. Xu, J. Am. Chem. Soc., 2012, 134, 5697-5705.

21 A.S.K. Hashmi, Angew. Chem. Int. Ed., 2010, 49, 5232-5241.

22 C. Obradors and A.M. Echavarren, Chem. Comm., 2014, 50, 16-28.

23 H. Schmidbaur and A. Schier, Organometallics, 2010, 29, 2-23 and references cited therein.

24 R.E.M. Brooner and R. Widenhoefer, Angew. Chem. Int. Ed., 2013, 52, 11714-11724.

25 L. Liu and G.B. Hammond, Chem. Soc. Rev., 2012, 41, 3129-3139.

26 D. Zuccaccia, L. Belpassi, A. Macchioni and F. Tarantelli, Eur. J. Inorg. Chem., 2013, 24, 4121-4135.

27 C.A. Gaggioli, G. Ciancaleoni, L. Biasiolo, G. Bistoni, D. Zuccaccia, L. Belpassi, P. Belanzoni and F. Tarantelli, Chem. Commun., 2015, 51, 5990-5993.

28 C.A. Gaggioli, G. Ciancaleoni, D. Zuccaccia, G. Bistoni, L. Belpassi, F. Tarantelli and P. Belanzoni, Organometallics, 2016, 35, 2275-2285.

29 C. Brouwer and C. He, Angew. Chem., Int. Ed., 2006, 45, 1744- 1747.

30 R. Gramage-Doria, R. Bellini, J. Rintjema and J.N.H. Reek, ChemCatChem, 2013, 5, 1084-1087.

31 A. Homs, C. Obradors, D. Lebœuf and A.M. Echavarren, Adv. Synth. Catal., 2014, 356, 221-228.

32 L. Biasiolo, G. Ciancaleoni, L. Belpassi, G. Bistoni, A. Macchioni, F. Tarantelli and D. Zuccaccia, Catal. Sci. Technol., 2015, 5, 1558-1567.

33 Y. Xu, X. Hu, S. Zhang, X. Xi and Y. Wu, ChemCatChem, 2016, 8, 262-267.

34 Y. Xia, A.S. Dudnik, V. Gevorgyan and Y. Li, J. Am. Chem. Soc., 2008, 130, 6940-6941.

35 P.W. Davies and N. Martin, Org. Lett., 2009, 11, 2293-2296.

36 V.M. Lau, C.F. Gorin and M.W. Kanan, Chem. Sci., 2014, 5, 4975-4979.

37 M. Jia, G. Cera, D. Perrotta, M. Monari and M. Bandini, Chem. Eur. J., 2014, 20, 9875-9878.

38 Z. Zhang, C. Liu, R.E. Kinder, X. Han, H. Qian and R.A. Widenhoefer, J. Am. Chem. Soc., 2006, 128, 9066-9073.

39 G.L. Hamilton, E.J. Kang, M. Mba and F.D. Toste, Science, 2007, 317, 496-499.

40 M. Bandini, A. Bottoni, M. Chiarucci, G. Cera and G.P. Miscione, J. Am. Chem. Soc., 2012, 134, 20690-20700.

41 K. Aikawa, M. Kojima and K. Mikami, Angew. Chem., Int. Ed., 2009, 48, 6073-6077.

42 G. Ciancaleoni, L. Belpassi, F. Tarantelli, D. Zuccaccia and A. Macchioni, Dalton Trans., 2013, 42, 4122-4131. 
43 D. Zuccaccia, L. Belpassi, L. Rocchigiani, F. Tarantelli and A. Macchioni, Inorg. Chem., 2010, 49, 3080-3082.

44 N. Salvi, L. Belpassi, D. Zuccaccia, F. Tarantelli, and A. Macchioni, J. Organomet. Chem., 2010, 695, 2679- 2686.

45 G. Ciancaleoni, L. Biasiolo, G. Bistoni, A. Macchioni, F. Tarantelli, D. Zuccaccia and L. Belpassi, Organometallics, 2013, 32, 4444-4447.

46 D. Zuccaccia, L. Belpassi, F. Tarantelli and A. Macchioni, J. Am. Chem. Soc., 2009, 131, 3170-3171.

47 Biasiolo, L.; Belpassi, L.; Ciancaleoni, G.; Macchioni, A.; Tarantelli, F.; Zuccaccia, D. Polyhedron 2015, 92, 52-59.

48 D. Weber, T.D. Jones, L. Adduci and M.R. Gagné, Angew. Chem., Int. Ed., 2012, 51, 2452-2456.

49 M. Jia and M. Bandini, ACS Catal., 2015, 5, 1638-1652 and reference cited therein.

50 L. Biasolo, M. Trinchillo, P. Belanzoni, L. Belpassi, V. Busico, G. Ciancaleoni, A. D'Amora, A. Macchioni, F. Tarantelli and D. Zuccaccia, Chem. Eur. J., 2014, 20, 14594-14598.

51 G. Ciancaleoni, L. Belpassi, D. Zuccaccia, F. Tarantelli and P. Belanzoni, ACS Catal. 2015, 5, 803-814.

52 M. Trinchillo, P. Belanzoni, L. Belpassi, L. Biasiolo, V. Busico, A. D’Amora, L. D’Amore, A. Del Zotto, F. Tarantelli, A. Tuzi and D. Zuccaccia, Organometallics, 2016, 35, 641-654.

53 G. Kovács, G. Ujaque and A. Lledós, J. Am. Chem. Soc., 2008, 130, 853 -864.

54 L. Biasiolo, A. Del Zotto and D. Zuccaccia, Organometallics, 2015, 34, 1759-1765.

55 L. Belpassi, I. Infante, F. Tarantelli and L. Visscher, J. Am. Chem. Soc., 2008, 130, 1048-1060.

56 N. Salvi, L. Belpassi and F. Tarantelli, Chem.-Eur. J., 2010, 16, 7231-7240.

57 P. Hohenberg and W. Kohn, Phys. Rev., 1964, 136, B864-B871.

58 W. Kohn and L. Sham, J. Phys. Rev., 1965, 140, A1133-A1138.

59 R.G. Parr and W. Yang, In Density-Functional Theory of Atoms and Molecules; Oxford University Press: New York, 1989.

60 M.J. Frisch, G.W. Trucks, H.B. Schlegel, G.E. Scuseria, M.A. Robb, J.R. Cheeseman, G. Scalmani, V. Barone, B. Mennucci, G.A. Petersson, H. Nakatsuji, M. Caricato, X. Li, H.P. Hratchian, A.F. Izmaylov, J. Bloino, G. Zheng, J.L. Sonnenberg, M. Hada, M. Ehara, K. Toyota, R. Fukuda, J. Hasegawa, M. Ishida, T. Nakajima, Y. Honda, O. Kitao, H. Nakai, T. Vreven, J.A. Montgomery, J.E. Jr. Peralta, F. Ogliaro, M. Bearpark, J.J. Heyd, E. Brothers, K.N. Kudin, V.N. Staroverov, R. Kobayashi, J. Normand, K. Raghavachari, A. Rendell, J.C. Burant, S.S. Iyengar, J. Tomasi, M. Cossi, N. Rega, J.M. Millam, M. Klene, J.E. Knox, J.B. Cross, V. Bakken, C. Adamo, J. Jaramillo, R. Gomperts, R.E. Stratmann, O. Yazyev, J. Austin, R. Cammi, C. Pomelli, J.W. Ochterski, R.L. Martin, K. Morokuma, V.G. Zakrzewski, G.A. Voth, P. 
Salvador, J.J. Dannenberg, S. Dapprich, A.D. Daniels, O. Farkas, J.B. Foresman, J.V. Ortiz, J. Cioslowski and D.J. Fox, Gaussian 09, revision A. 02 Gaussian Inc., Wallingford CT, 2009.

61 A.D. Becke, Phys. Rev. A, 1988, 38, 3098-3100.

62 J.P. Perdew and Y. Wang, Phys. Rev. B, 1986, 33, 8822-8824.

63 D. Andræ, U. Häeußermann, M. Dolg, H. Stoll and H. Preuß, Theor. Chim. Acta, 1990, 77, 123-141. 64 F. Weigend and R. Ahlrichs, Phys. Chem. Chem. Phys., 2005, 7, 3297-3305.

65 F. Neese, WIREs Comput. Mol. Sci., 2012, 2, 73-78.

66 S.J. Grimme, Chem. Phys., 2006, 124, 034108.

67 G. Ciancaleoni, S. Rampino, D. Zuccaccia, F. Tarantelli, P. Belanzoni and L. Belpassi, J. Chem. Theory Comput., 2014, 10, 1021-1034.

68 R.H. Kang, H. Chen, S. Shaik and J. Yao, J. Chem. Theory Comput., 2011, 7, 4002-4011.

69 R.H. Kang, W. Lai, J. Yao, S. Shaik and H. Chen, J. Chem. Theory Comput., 2012, 8, 3119-3127.

70 E.J. Baerends, D.E. Ellis and P. Ross, Chem. Phys., 1973, 2, 41-51.

71 G. te Velde, F.M. Bickelhaupt, E.J. Baerends, C.F. Guerra and S.J.A. van Gisbergen, J. Comput. Chem., 2001, 22, 931-967.

72 SCM, Theoretical Chemistry, ADF User's Guide, Release 2013.01, Vrije Universiteit, Amsterdam, The Netherlands, 2013, https://www.scm.com.

73 E. van Lenthe, E.J. Baerends and J. G. Snijders, J. Chem. Phys., 1994, 101, 9783-9792.

74 E. van Lenthe, R. van Leeuwen, E.J. Baerends and J. G. Snijders, Int. J. Quantum Chem., 1996, 57, 281-293.

75 K. M. Azzopardi, G. Bistoni, G. Ciancaleoni, F. Tarantelli, D. Zuccaccia and L. Belpassi, Dalton Trans., 2015, 44, 13999-14007.

76 G. Ciancaleoni, N. Scafuri, G. Bistoni, A. Macchioni, F. Tarantelli, D. Zuccaccia and L. Belpassi, Inorg. Chem., 2014, 53, 9907-9916.

77 O. Eisenstein and R. Hoffmann, J. Am. Chem. Soc., 1981, 103, 4308-4320.

78 A. Fürstner and P.W. Davies, Angew. Chem., Int. Ed., 2007, 46, 3410-3449.

79 G. Bistoni, S. Rampino, F. Tarantelli and L. Belpassi, J. Chem. Phys., 2015, 142, 084112.

80 G. Bistoni, P. Belanzoni, L. Belpassi and F. Tarantelli, J. Phys. Chem. A, 2016, 120, 5239-5247. 